\title{
Gellner e o último samurai
}

CÉSAR Weyne

\author{
Edward Zwick, The Last Samurai. Warner Brothers \\ Pictures, 2003
}

Neste exercício de reflexão utilizaremos o filme "O Último Samurai" (Edward Zwick, 2003) como ilustração da transição de uma sociedade agro-letrada para uma sociedade industrial, passagem que é ponto de destaque na teoria de Ernest Gellner em seu livro Nações e Nacionalismos (1993), a "fusão da cultura e do Estado"(GELLNER, p.29).

A inspiração para tal partiu do próprio Gellner ao citar que:

a sociedade moderna é como um exército moderno, apenas numa escala maior. Proporciona a todos os recrutas uma formação bastante prolongada e muito completa, dando maior ênfase a algumas qualificações comuns: ler e escrever, aritmética, hábitos de trabalho e funções sociais básicas, familiarização com funções técnicas e sociais básicas. (GELLNER, p.49)

É a assunção dessas novas técnicas e funções trazidas pelo exército moderno estadunidense sobre a cultura tradicional japonesa que nos chama a atenção no filme. Assim, começaremos com a definição de nossos principais conceitos.

O primeiro é o de sociedade agro-letrada. Sociedade possuidora de uma tecnologia estável, com avanço lento, onde a educação funcionava como fator de diferenciação, estabelecia uma cultura como superior e as diferentes desta como culturas inferiores. Pautada primordialmente na vida prática, sua "classe governante é constituída por uma pequena minoria da população rigidamente separada da grande maioria dos produtores agrícolas diretos, isto é, dos camponeses" (GELLNER, p.23).

\section{$\overline{\text { César Weyne }}$}

Mestre em Políticas Públicas e Sociedade pela Universidade Estadual do Ceará. 
Já a sociedade industrial avançada é caracterizada pela inovação tecnológica permanente, por um "crescimento sustentado e contínuo" (GELLNER, p.41). Nela a cultura superior se impõe por meio de um sistema educacional estandardizado, padronizado, que busca uma igualização e homogeneização, uma massificação da sociedade. É um grupamento social " que se tornou dependente tanto do crescimento econômico como do conhecimento" (GELLNER, p.44), ou, melhor definido:

uma sociedade baseada numa tecnologia muito poderosa e na expectativa do crescimento prolongado, que exige uma divisão do trabalho móvel e uma comunicação contínua, freqüente e exata entre estranhos, envolvendo uma partilha de significado explícito, emitido através de um idioma standardizado e, se necessário, escrito. (GELLNER, p.58)

O filme se passa na década de 1870 quando é enviado ao Japão o Capitão do exército americano Nathan Algren (Tom Cruise) com a missão de treinar as tropas do Imperador Meiji (Shichinosuke Nakamura), que nunca haviam, sequer, visto uma espingarda. Uma modernização que não se restringe ao exército como podemos ver na implantação da ferrovia que é feita com remoções e casas queimadas.

Havia também a intenção de celebrar um contrato de exclusividade para o fornecimento de armas entre os Estados Unidos da América - EUA e o Japão, para além de adestrar esse exército que deveria eliminar os últimos samurais que "defendem os valores culturais japoneses contra a invasão ocidental".

É um período de modernização acelerada do Japão, definido como a Restauração Meiji (1867-1912). Uma época de rupturas, em que a pólvora quis fazer desaparecer a espada, onde foram promovidas reformas políticas e sociais que visavam prover ao Japão o que havia de melhor no mundo do conhecimento e da tecnologia, onde aconteceram óbvios movimentos de resistência a essa modernização como a Rebelião Satsuma (1877) que inspira a trama do filme.

Assim, ao buscar paralelo histórico, Saigo Takamori seria Katsumoto (personagem de Ken Watanabe), morto aos 50 anos, 
em 1877. Tido como o derradeiro samurai, o último grande mestre-de-armas que, com a espada na mão, lutou até o fim para preservar sua tradição marcial.

No início do filme o Capitão Algren é levado pelos "avanços da mecânica e das oportunidades comerciais" a aceitar o desafio de Omura (Masato Harada) para fazer o "Japão se tornar um país civilizado". Podemos notar aqui que civilizado pode assumir conotação oposta a de selvagem, termo utilizado em outros momentos em referência aos samurais, em antagonismo a uma nova cultura erudita.

Nathan aceita o convite afirmando que "aparentemente é o único trabalho para o qual tenho jeito" e temos o início de uma batalha entre um "herói genuíno" contra samurais selvagens ou, como melhor define o personagem Simon Graham (Timothy Spall), teremos "o antigo e o moderno lutando pela alma do Japão".

Omura recebe os especialistas do exército americano e afirma que todos "esperamos desfrutar da mesma harmonia nacional que desfrutam em suas pátrias", sugerindo que enfrenta dificuldades nessa transição para a modernização de seu país, e logo passam ao treinamento para "transformar camponeses em soldados".

No primeiro combate, toda a força da mitologia construída pelos samurais recai sobre os jovens soldados e a modernização é derrotada inicialmente. Aceitar a disciplina do exército moderno parece ser difícil. Há dificuldade em manter alinhamentos, formação, em desempenhar novas ações motoras como municiar as armas e colocar, utilizar a baioneta. Contudo o aprendizado é indispensável, "a antiga estabilidade da estrutura de papéis sociais é, simplesmente, incompatível com o crescimento e a inovação. A inovação significa fazer coisas novas, cujos limites não podem ser os mesmos" (GELLNER, p.44) e, mesmo derrotados nessa primeira batalha, os soldados continuarão seu treinamento durante todo o inverno.

Nesse conflito nos deparamos com as diferenças entre a cultura moderna (erudita) e a selvagem. Os soldados estão armados com fuzis enquanto os samurais portam espadas. Usar arma de fogo é desonra para o samurai e sua espada é sua alma. Diferente das armas e uniformes padronizados do exercito moderno, cada 
armadura, espada de samurai carrega marcas individuais, uma história particular.

Capturado ao final da primeira batalha, Algren é apresentado a outras características da cultura samurai como a honra, que leva o guerreiro a tirar a própria vida por não suportar a vergonha de uma derrota, e o ato de "não se apresentar (que) é considerado extremamente rude, mesmo entre inimigos" como dispara seu captor, Katsumoto.

Embora a cultura samurai seja caracterizada como selvagem, o personagem de Cruise nos lembra que são "selvagens com arcos e flechas cuja ocupação, nos últimos mil anos, é lutar". E faz questão de anotar, "devotam-se à busca da perfeição em qualquer coisa que façam. Jamais vi tamanha disciplina".

Samurais treinam com espada, atiram com arco, fazem montaria, apuram técnicas de combate corporal e, assim como o exército moderno, possuem disciplina, mas de forma diferente. São portadores de técnicas e disciplina próprias, passadas por um sistema de educação diferente, com as características da sociedade agro-letrada.

Interessante é destacar que tanto o exército moderno, quanto os samurais, rendem honras ao Imperador, o que ratifica que não é uma luta para a libertação de um determinado grupo, mas sim uma disputa pelo modelo de organização da sociedade nipônica.

Em um dos diversos diálogos, devido a sua curiosidade sobre a cultura estadunidense, Katsumoto pergunta ao Capitão sobre as patentes militares, ponto que denota a maior hierarquização e insinua um maior número de especialistas no exército moderno, assim como na sociedade industrial. Contudo, Gellner enfatiza que "na sociedade industrial, apesar do elevado número de especializações, a distância entre os especialistas é muito menor" (GELLNER, p.48), ou seja, o acúmulo de habilidades e conhecimento que separa um sargento de um oficial de patente imediatamente superior é bem menor do que o que separa um samurai de seu superior imediato.

Após um ano de treinamento, de formação, de educação, o exército moderno japonês já manuseia morteiros e armas de repetição. A cidade está rabiscada por cabos de transmissão de energia 
e a batalha para a modernização também passa pelo Conselho Imperial, pois o Estado moderno "determina a norma para a legitimação das unidades políticas no mundo moderno" (GELLNER, p.79). Nele, leis foram aprovadas contra os samurais e os antes temidos, respeitados, passam a ser humilhados - fato exemplificado por cena onde um samurai é obrigado a se desfazer de sua espada ("sua alma") e tem seu coque (marca de sua individualidade) cortado por soldados uniformizados com cortes de cabelo padronizados.

Nessa passagem pelo Conselho Imperial, quando o Imperador Meiji não recebe a espada de Katsumoto e o aprisiona, age como que aprisionasse o Japão agro-letrado para que o Japão industrializado pudesse existir em sua plenitude; para que, após novecentos anos de tradição samurai, o exército moderno ocupasse seu lugar nessa trajetória.

Essa transição é dramatizada na última batalha com o sangue de irmãos, de "patriotas", samurais e soldados, a regar o solo para o florescer do novo Japão. Contudo, com o desenrolar do filme, percebemos que o modo antigo, selvagem, não precisa necessariamente desaparecer para a emergência do novo. Ele pode ser re-significado.

Como nos diz Gellner "o processo de industrialização realizou-se em fases sucessivas e segundo condições diferentes, dando origem a várias rivalidades novas, com novos ganhos a obter e novas perdas a evitar." (GELLNER, p.84). Isso fica bem ilustrado na fala do Imperador quando afirma: "Sonhei com um Japão unificado, com uma país forte, independente e moderno. Agora temos ferrovias, canhões, roupas ocidentais... Mas não podemos esquecer quem somos, nem de onde viemos" e não celebra o esperado contrato de fornecimento de armas com os EUA naquele momento. Porém, "os dias dos samurais acabaram. Nações, como homens, como às vezes se diz, tem destino próprio.", diz o Sr. Graham ao encerrar o filme. O processo de transição da sociedade agro-letrada para uma sociedade industrial havia começado e seguiria seu caminho. 


\section{REFERÊNCIAS}

GELLNER, Ernest. Nações e nacionalismos. Lisboa: Gradiva, 1993. SCHILLING, Voltaire. Japão, o último samurai. Disponível em: <http://educaterra.terra.com.br/voltaire/ mundo/2004/03/01/001.htm> . Acesso em: 07 de setembro de 2015.

YAMAZATO, Augusto. História Ilustrada do Japão. São Paulo: Editora 5 cores, 1967.

O Último Samurai (original: The Last Samurai). Direção: Edward Zwick. Produção: Tom Cruise, Tom Engelman, Marshall Herskovits, Scott Kroopf, Paula Wagner e Edward Zwick. Intérpretes: Tom Cruise, Shichinosuke Nakamura, Ken Watanabe, Masato Harada, Billy Connolly, Tony Goldwyn, Timothy Spall e outros. Roteiro: John Logan, Edward Zwick, Marshall Herskovitz. Música: Hans Zimmer. EUA: Warner Brothers Pictures, 2003. DVD 154 min., widescreen, color. 